\section{First record and description of the female of Diastephanus chinnarensis Sureshan (Hymenoptera: Stephanidae) from India}

\section{S. Sheela ${ }^{1} \&$ S.N. Ghosh ${ }^{2}$}

${ }^{1}$ Zoological Survey of India, M-Block, New Alipore, Kolkata, West Bengal 700053, India

${ }^{2}$ West Bengal Biodiversity Board, Paribesh Bhavan, Salt Lake,

Kolkata, West Bengal 700098, India

Email: ${ }^{1}$ sheela_saroj@yahoo.com, ${ }^{2}$ soumyendraghosh@yahoo.co.in

Members of the genus Diastephanus Enderlein (Hymenoptera: Stephanidae) are believed to be parasitic on wood-boring beetles and their biology is little explored. The genus contains 48 species all over the world distributed in the Oriental, Ethiopean and Australian regions, out of which 11 species are known from India (Elliot 1922; Sureshan \& Narendran 1997; Sureshan 1997; Narendran et al. 2002; Narendran \& Sureshan 2003). Sureshan (1997) described D. chinnarensis from Kerala, India based on a single male specimen. One female specimen of Diastephanus was collected from Arunachal Pradesh, India, and on detailed studies it shows close affinity to $D$. chinnarensis Sureshan. Here the specimen is being reported as the female of D. chinnarensis and is described and illustrated. This is the first record of the female of $D$. chinnarensis Sureshan. The material for the present study is deposited in the National Zoological Collections of the Zoological Survey of India, Kolkata.

\section{Diastephanus chinnarensis Sureshan} (Figs. $1 \&$ 2)

\section{Material examined \\ Female, 28.iv.2001, Bhalukpong (West Kameng), Arunachal Pradesh, Coll. S.N. Ghosh, NZC 10072/H3.}

Date of publication 26 March 2009

ISSN 0974-7907 (online) | 0974-7893 (print)

Editor: P.M. Sureshan

\section{Manuscript details:}

Ms \# 01784

Received 21 May 2007

Final revised received 04 March 2008

Finally accepted 09 June 2008

Citation: Sheela, S. \& S.N. Ghosh (2009). First record and description of the female of Diastephanus chinnarensis Sureshan (Hymenoptera: Stephanidae) from India. Journal of Threatened Taxa 1(3): 182-183.

Copyright: (C) S. Sheela \& S.N. Ghosh 2009. Creative Commons Attribution 3.0 Unported License. JoTT allows unrestricted use of this article in any medium for non-profit purposes, reproduction and distribution by providing adequate credit to the authors and the source of publication.

Acknowledgements: The authors are grateful to the Director, Zoological Survey of India, for providing necessary facilities for this study; the kind help from Mr. C. Radhakrishnan, Officer- in- charge, Western Ghats Regional Station, Zoological Survey of India who provided necessary facilities for measuring and drawing the specimen as well as the type specimen of $D$. chinnarensis Sureshan for comparative study; to Dr. T.C. Narendran, Emeritus Professor of Calicut University, Kerala and Dr. P.M. Sureshan, Scientist-B of Estuarine Biological Station, Orissa for sending valuable reprints necessary for this study.

\section{OPEN ACCESS | FREE DOWNLOAD}

Distribution: India (Arunachal Pradesh, Kerala).

\section{Diagnostic features}

Length-13.65 mm

(excluding

ovipositor), ovipositor length $11.5 \mathrm{~mm}$. Black; mandibles smooth, brownish-yellow; teeth black; clypeus, area above clypeus, in between eyes and in between toruli up to front tubercle (including tubercle) forms three yellowish-white bands; area starting with toruli continues as two black bands and spreads over vertex; tip of front tubercle black; area just below eyes yellowish-white; gena black; eyes reddish-brown with black patches; posterior pair of frontal tubercles black; front ocellus reddish-brown; scape, pedicel and basal segments of antennae brownish-yellow, blackening upwards. Thorax, petiole and abdomen black; tip of last abdominal sternum brownish-yellow; posterior margin of pronotum and scutellum yellowish-grey; ovipositor brownish-red, sheaths black with a sub apical yellowish-white band, length of which is equal to length of remaining apical black portion; fore and mid coxae, trochanters and base of femora with tinge of reddish-brown; base of tibiae yellowish-white, more clear on mid tibia; basi-tarsi pale yellow, remaining tarsal segments brownish-yellow; other parts black; hind coxa, trochanter, femur black; tarsi brownish-yellow with tinge of black; tibiae with a brownish-yellow band starting sub basally up to swollen portion on dorsal side; wings clear transparent; veins brownish-black.

Head: With five tubercles; head width: length in anterior view 46: 50, in dorsal view 45: 40; frons transversely striate except around tubercle, where it is obliquely striate; ocell-ocular area transversely carinate; behind very finely transversely striate; gena smooth, shining, posterior margin of head sharply carinate; vertex with three carinae in between posterior ocelli; POL $3 \mathrm{x}$ OOL; lengths of antennal segments: scape-8, pedicel $-5, \mathrm{~F} 1-$ 10, F2, F3, F4-15 each.

Mesosoma: Neck in dorsal view with fine transverse striations; lateral side very closely striate, reticulate; striations feeble on ventral side, looking minutely reticulate in certain reflections of light; pronotum with fine superficial rugoreticulum; anterior portion of mesoscutum finely shagreened; posterior half widely pitted, interstices shagreened; mesopleuron finely and minutely reticulate, shagreened with shallow, scattered pits along middle, posterior portion sunken, about half of anterior portion aciculate and with minute appressed silvery hairs; scutellum separated from mesoscutum by two deep grooves in the middle which is smooth inside and either side with posterioly converging concentric striations on which fine lengthy reticulations visible in certain reflections of light; scutellum anteriorly with superficial reticulations, somewhat ' $\mathrm{V}$ ' shaped and going normal posteriorly; metanotum grooved with long ridges, thorax emarginated in this groove; propodeum completely studded with large close pits, pits weakly and interstices strongly shagreened; posterior margin carinate with two pairs of broad, hexagonal pits; about half of upper portion of metapleuron aciculate, lower portion finely reticulate, metapleuron by the side of mid coxa with five or six transverse carinae, above that is a sub triangular smooth depression, below

Abbreviations: F1-F4 - Funicular segments 1 to 4; NZC - National Zoological Collections, Zoological Survey of India; OOL - Ocell-ocular length; POL - Post-ocellar length 


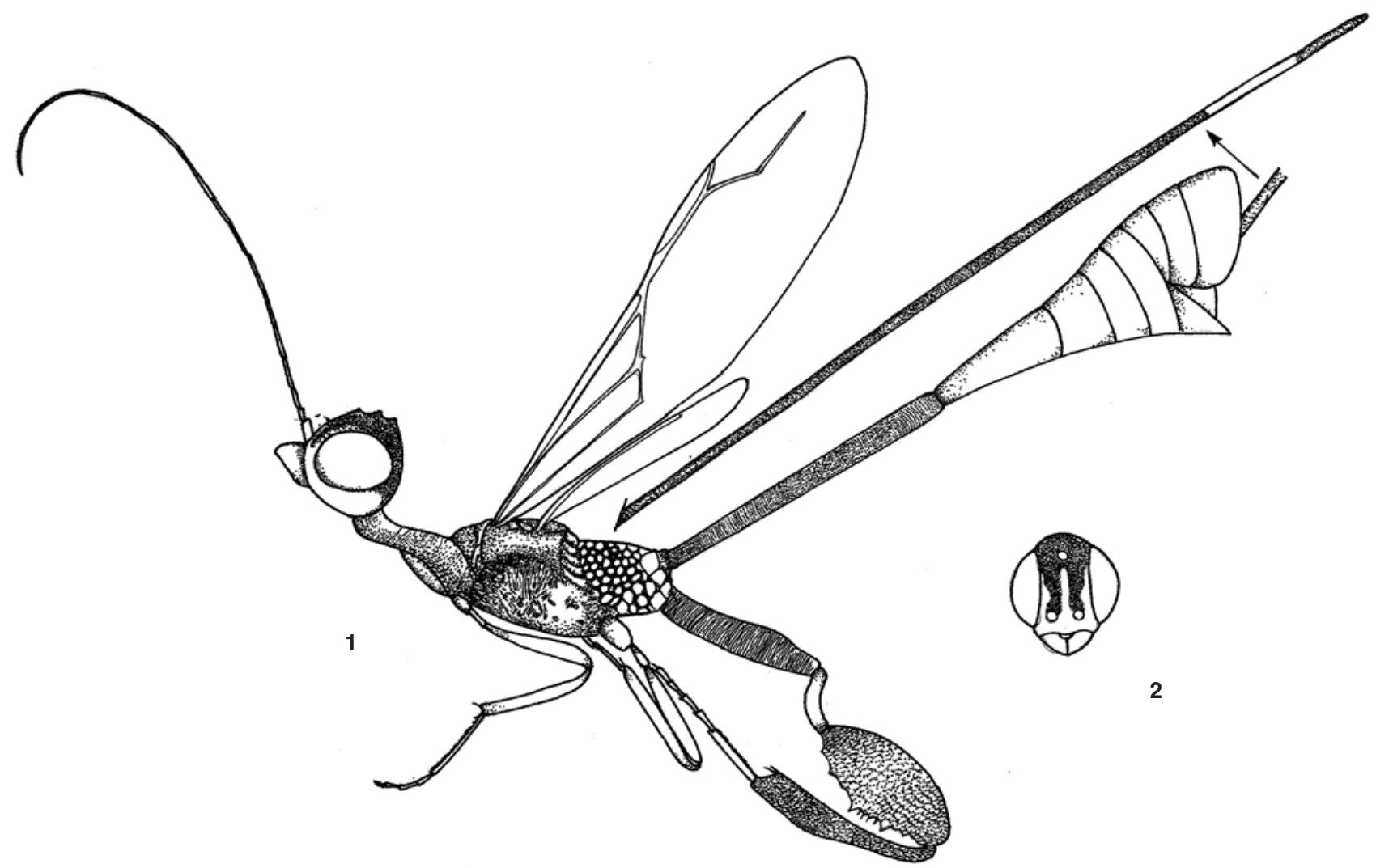

Figures 1-2. Diasterphanus chinnarensis Sureshan Female. 1 - Body profile; 2 - Head front view

which are rectangular, polished, irregularly punctuate portion; remaining portion widely regularly pitted, interstices smooth; foreleg polished, superficially sculptured in certain reflections of light; coxa and femur faintly transversely striate, tibia punctuate at base, from swollen portion, sculpture concealed by a thick tuft of grey, blunt decumbent hairs, sides of hair covered parts faintly shagreened; tarsi opaque, hairy; mid coxa weakly transversely rugulose; trochanter smooth polished; femur very faintly rugulose, shining; tibia dorsally smooth laterally and ventrally very weakly rugulose; tarsi opaque with sparse hairs; hind leg with sharp sculpture; coxa strongly transversely striate; trochanters in certain reflections finely shagreened; femur finely reticulate (somewhat elongate manner), tibia reticulate, depressed median portion with very small fine reticulations; tarsi opaque.

Metasoma: Petiole shorter than gaster; finely transversely striate; base dorsally minutely reticulate; posterior margin smooth, polished; anterior margin carinate; a few scattered decumbent hairs (mostly on anterior half); laterally more or less compressed; broadening posteriorly; a very small median carina, two short sub median carinae, two long lateral carinae almost as long as petiole and two ventral carinae (more than 1/ 3 of petiole) at base; gaster smooth, polished; but on closer examination appears very finely and superficially minutely reticulate.

\section{Remarks}

Comparative study of the present specimen with the holotype (male) of D. chinnarensis shows close affinity between the two except for the differences: $D$. chinnarensis male has two transverse carinae between posterior ocelli, pronotum with two yellow triangular patches joined together, gaster with a yellow patch and propodeum finely reticulate, shining with scattered shallow pits. In the current female specimen there are three carinae between posterior ocelli, pronotum with yellow patch crescent shaped, gaster without yellow patch, and propodeum with deep, close pits and interstices finely reticulate. Assuming the above differences as variations or associated with sexual dimorphism, the current specimen is being reported here as the female of D. chinnarensis Sureshan. More specimens of both sexes are to be collected and studied in order to reach a final conclusion.

\section{References}

Elliot, E.W. (1922). Monograph of the Hymenopterous family Stephanidae. Proceedings of the Zoological Society of London 92: $705-831$.

Narendran T.C., L. Kishore \& K.A. Karmaly (2002). A New species of Diastephanus Enderlein ( Hymenoptera: Stephanidae) from Christmas Islands. Proceedings of the Zoological Society of Calcutta 55(1): 6972 .

Narendran, T.C. \& P.M. Sureshan (2003). Systematic studies on Diastephanus Enderlein (Hymenoptera: Stephanoidea: Stephanidae) of Indian subcontinent. Entomon 28(2): 115-138.

Sureshan, P.M. (1997). A new species of Diastephanus Enderlein (Hymenoptera: Stephanidae) from India. Bioved $8:$ 89-92.

Sureshan, P.M. \& T.C. Narendran (1997). A new species of Diastephanus Enderlein (Hymenoptera: Stephanidae) from India. Geobios new Reports 16(1): 25-27. 